\title{
Assessment of Direct Cost of Treatment of Ischemic Heart Disease Patient in Tertiary Care Hospital in Karachi
}

\author{
Khan MA ${ }^{1 *}$, Mairaj $\mathbf{M}^{5}$, Khan A $^{5}$, Ahsan $\mathbf{M}^{5}$, Ali SI ${ }^{1}$, Nisa $\mathbf{Z U}^{2}$, Alam $\mathbf{S}^{2}$, Bushra $\mathbf{R}^{3}$, zafar $\mathrm{F}^{4}$ and Fatima $\mathbf{R}^{1}$ \\ ${ }^{1}$ Department of Pharmacy Practice, Faculty of Pharmacy, Ziauddin University, Karachi, Pakistan \\ ${ }^{2}$ Department of Pharmaceutics, Faculty of Pharmacy, Ziauddin University, Karachi, Pakistan \\ ${ }^{3}$ Department of pharmaceutics, Dow college of Pharmacy, Dow University of health sciences Karachi, Pakistan \\ ${ }^{4}$ Department of Pharmaceutics, Faculty of Pharmacy, University of Karachi \\ ${ }^{5}$ Ziauddin Faculty of Pharmacy, Ziauddin University, Karachi, Pakistan
}

\begin{abstract}
Purpose: The objective of the study is to determine the direct cost of treatment of ischemic heart disease patient in tertiary care hospital in Karachi.

Methods: This is a retrospective cost of illness study conducted in tertiary care hospital in Karachi between May 2015 to October 2015. All patients were included in the study diagnosed with IHD during admission at hospital between a period of August 2014 to June 2015. The research study conducted in a 100 beds tertiary care hospital attached with a medical university located in Karachi. All in patients were included in the study with an age group of (>18 years old) who were diagnosed, or suffered from IHD (Ischemic heart disease) (with respect to the patient file) were included in the study. Over all we evaluated 700 files of cardiovascular disease patients from which we separated the IHD patients' files. From separated IHD files we selected the most relevant 75 IHD patient files. Patient clinical information were obtained from the patients 'medical file, and added with the unit cost of services to determine expense.

Results: Overall most relevant 75 patient files were selected for the study purpose from the 700 files of cardiovascular disease patients' files. Most of the patients were male, aged from 30 to 85 years. Co morbidity was found in $60(80 \%)$ patients, a single co morbid condition consist of $26(43.3 \%)$ patients and two or more consist of $31(51.6 \%)$ patients. Hypertension and diabetes were most commonly found co morbid condition in ischemic heart disease patients. Chest pain, Shortness of breath were the most commonly symptoms found in ischemic heart disease patients. Most commonly prescribed medication were aspirin $77(61.60 \%)$, clopidogrel $73(58.40 \%)$, nitro-glycerine $35(28 \%)$, Enoxaparin $38(30.40 \%)$ and Atorvastatin $41(32.80 \%)$. The mean total direct cost was Rs. 359975. The cost component included were length of stay cost Rs. 27697; laboratory and diagnosis cost Rs. 37684; medication cost Rs. 21019 and surgical procedure cost Rs. 273574. The percentage of the total expense according to the each component was as follows: length of stay expense $(7.69 \%)$, laboratory and diagnosis cost $(10.47 \%)$, hospital stay cost $(7.69 \%)$, surgical procedures $(75.99 \%)$. Surgical procedure was main component of cost of treatment of Ischemic heart disease patients. The median hospital stay was 2 days in ischemic heart disease patients.
\end{abstract}

Conclusion: IHD is associated with high economic burden on society. Among different component of direct cost of treatment of IHD, surgical procedure was the main component of cost of treatment of ischemic heart disease patients.

Keywords: Ischemic hearts disease; Length of stay; Direct cost of treatment; Tertiary care hospital

\section{Introduction}

Coronary Heart Disease (CHD), sometimes described as Coronary Artery Disease (CAD) or Ischaemic Heart Disease (IHD), is a condition in which the vascular supply to the heart is impeded by atheroma, thrombosis or spasm of coronary arteries. This may impair the supply of oxygenated blood to cardiac tissue sufficiently to cause myocardial ischaemia which, if severe or prolonged, may cause the death of cardiac muscle cells. Similarities in the development of atheromatous plaques in other vasculature, in particular the carotid arteries, with the resultant cerebral ischaemia has resulted in the term Cardiovascular Disease (CVD) being adopted to incorporate $\mathrm{CHD}$, cerebrovascular disease and peripheral vascular disease [1].

IHD caused by atherosclerosis of the epicardial vessels leading to CHD is the main etiology of IHD. This process begins early in life, often not being clinically manifest until the middle-aged years and beyond. IHD may present as an acute coronary syndrome (acute coronary syndrome includes unstable angina, non-ST-segment elevation myocardial infarction or ST-segment elevation myocardial infarction; chronic stable exertional angina pectoris, and ischemia without clinical symptoms. Coronary artery vasospasm (variant or Prinzmetal angina) produces similar symptoms but is not caused by atherosclerosis. Other manifestations of atherosclerosis include heart failure, arrhythmias, cerebrovascular disease (stroke), and peripheral vascular disease. The American Heart Association, the American College of Cardiology, and the European Society of Cardiology have published management

*Corresponding author: Khan MA, Associate Professor, Faculty of Pharmacy Ziauddin University, Pharmacy Practice, Ziauddin University Clifton, Karachi, Sindh 74000, Pakistan, Tel: 03412489472; E-mail: maqsoodkhan711@yahoo.com

Received January 18, 2017; Accepted February 02, 2017; Published February 17,2017

Citation: Khan MA, Mairaj M, Khan A, Ahsan M, Ali SI, et al. (2017) Assessment of Direct Cost of Treatment of Ischemic Heart Disease Patient in Tertiary Care Hospital in Karachi. J Bioequiv Availab 9: 353-358. doi: 10.4172/jbb.1000324

Copyright: @ 2017 Khan MA, et al. This is an open-access article distributed under the terms of the Creative Commons Attribution License, which permits unrestricted use, distribution, and reproduction in any medium, provided the original author and source are credited. 
guidelines for stable and unstable angina [2-4].

IHD is announced as the highly costly form of cardiovascular disease in the United States in 2010. In American individuals the prevalence of ischemic heart disease was found among age group of above 20 years was $7.9 \%$ i.e., $7 \%$ in women and $9.1 \%$ in men [5].

Major concern for all the countries is the expense due to IHD; research perform in UK, Thailand, India, China, and several other nations, have pointed out this important issue associated with the financial aspects of the diseases. For example, the estimated direct and indirect cost of CAD in the US for 2010 was $\$ 177.1$ billion. There is huge financial burden in UK due to CAD in 2004 and the estimated cost due to this disease was $£ 8.47$ billion per year (US $\$ 15.52$ billion, average exchange rate for year 2004 was 1.8326). CAD expense is a major part of the total expense of the health care system which is around $40.7 \%$. Most of the part of cost was associated to inpatients facility which represent $70 \%$ of the healthcare expense and drug treatment [6].

There are few studies available in Pakistan which representing the information related to cost of treatment of disease. The main objective of the study was to analyse the direct expense of management of hospitalized patients with IHD in a tertiary care centre (Figure 1) [7].

\section{Methodology}

\section{Study design}

This was a retrospective and cost of illness study directed from hospital point of view. The Study length was 5 months. This study was led from May 2015 to October 2015. The study was finished in a 100 beds tertiary care centre attached with a medical university found in Karachi. Examine consent was taken from the hospital administration.

\section{Patients}

Inpatients were incorporated with age more than 18 years old who were related, or determined to have IHD (Ischemic coronary illness).

\section{Sample size}

Over all we assessed 700 documents of cardiovascular infection patients from which we isolated the IHD patients' records. From isolated IHD records we finalized the most significant 75 IHD persistent documents.

\section{Data collection}

Patients information gathered comprise of demographic characteristics including age, gender, smoking, occupation, comorbidity, laboratory and diagnosis, drug and length of stay at

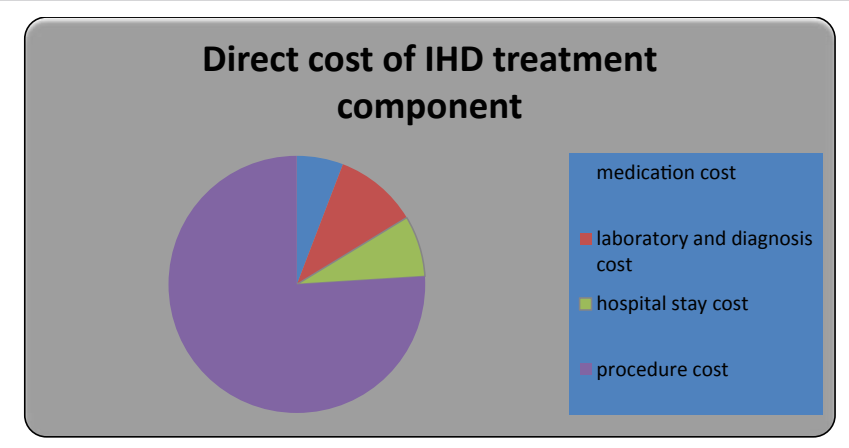

Figure 1: Direct cost of IHD treatment component. hospital was taken from the patient record document. The patient records were checked on by 4 prepared analysts, who utilized an organized frame to record the required data, and the most important of these were assessed.

\section{Cost calculation}

All the information, related to the resources needed to treat the disease were arranged. Patient clinical information were obtained from the patients' medical file, and added with the unit cost of services obtained from the hospital record including medication, procedures and bed utilization to determine direct medical expense.

\section{Statistical analysis}

Initially all the data were tabulated in the excel sheet and specific coding were used for each variable. Frequencies, percentages, means, medians were determined by using descriptive statistical analysis of spss version 15 and univariate analysis were performed using all the variables recorded on admission, the demographical characteristics, laboratory and diagnostic data, and the number of days of hospitalization. Pearson correlation analysis and spearman correlation analysis was used to investigate the relationship. All $\mathrm{P}$ value of $<0.05$ was considered statistically significant.

\section{Results}

\section{Demographic characteristics}

Total 600 cardiac patient files were reviewed and 75 patients' files were selected that were diagnosed with ischemic heart disease from March 2014 to March 2015. Demographic information like age, gender, smoking, occupation was recorded from the patient file. Seventy patients were adults with the mean age of $58.4 \pm 10.8$ years. Seventy nine percent patient were male and twenty one percent patient were female. Twenty three percent patients were found with smoking and seventy seven percent patient were found without smoking. Sixty seven percent patient were having no occupation and fourteen percent patient were related to their own business. Chest pain and shortness of breath were most commonly found symptoms in ischemic heart patient. Diagnosis and surgical procedures were also recorded. Demographic characteristics are summarized in Table 1.

\section{Co morbidity and length of stay}

Co-morbidity and length of stay of the patient hospitalized due to ischemic heart disease summarized in Table 2. Co-morbidity was found in $60(80 \%)$ patients, a single co morbid condition existed 26 (43.3\%) patients and two or more associated in 31 (51.6\%) patients. Comorbidity of the patients were Diabetes mellitus, hypertention, COPD, kidney disease, testicular cancer, Wolff-Parkinson-White syndrome (WPW), cerebrovascular disease, acid peptic disease, Dyslipidemia and Benign prostatic hyperplasia (BPH). Diabetes and hyper-tension were most commonly present in Ischemic heart disease patients. Median Length of stay in hospital was 2 days in patients hospitalized due to ischemic heart disease (Table 3 ).

\section{Direct cost of treatment in hospitalized patient due to ischemic heart disease}

Direct cost of treatment summarized in Table 4. The mean total cost was Rs. 359975. The over view of each component was length of stay cost Rs. 27697; laboratory and diagnosis cost Rs. 37684; medication cost Rs. 21019 and surgical procedure cost Rs. 273574. The percentage of the total cost according to the each part was mention as: length of 
Citation: Khan MA, Mairaj M, Khan A, Ahsan M, Ali SI, et al. (2017) Assessment of Direct Cost of Treatment of Ischemic Heart Disease Patient in Tertiary Care Hospital in Karachi. J Bioequiv Availab 9: 353-358. doi: 10.4172/jbb. 1000324

\begin{tabular}{|c|c|c|}
\hline Age & Frequency & Percentage \\
\hline $20-30$ & 1 & $1.33 \%$ \\
\hline $31-40$ & 4 & $5.33 \%$ \\
\hline $41-50$ & 12 & $16 \%$ \\
\hline $51-60$ & 29 & $38.66 \%$ \\
\hline $61-70$ & 21 & $28 \%$ \\
\hline $71-80$ & 6 & $8 \%$ \\
\hline $81-90$ & 2 & $2.66 \%$ \\
\hline Mean age years & $58 \pm 11$ & - \\
\hline \multicolumn{3}{|c|}{ Gender } \\
\hline Male & 59 & $78.66 \%$ \\
\hline female & 16 & $21.33 \%$ \\
\hline \multicolumn{3}{|c|}{ Smoking } \\
\hline Smoking & $1: 17$ & $22.66 \%$ \\
\hline Non-smoking & $2: 58$ & $77.33 \%$ \\
\hline \multicolumn{3}{|c|}{ Occupation } \\
\hline None & 28 & $37.33 \%$ \\
\hline Buisnessman/women & 11 & $14.66 \%$ \\
\hline Housewife & 10 & $13.33 \%$ \\
\hline Retired & 14 & $18.66 \%$ \\
\hline Wapda/Government & 3 & $4 \%$ \\
\hline Private & 3 & $4 \%$ \\
\hline Doctor & 2 & $2.66 \%$ \\
\hline Banker & 1 & $1.33 \%$ \\
\hline Proffessor & 1 & $1.33 \%$ \\
\hline Shop keeper & 1 & $1.33 \%$ \\
\hline Lawyer & 1 & $1.33 \%$ \\
\hline
\end{tabular}

Table 1: Demographic characteristics.

\begin{tabular}{|c|c|c|}
\hline Comorbidity & N & 4 \\
\hline Diabetes & 22 & 5.33 \\
\hline Hypertention & 24 & 29.33 \\
\hline Diabetes and hypertention & 1 & 32 \\
\hline COPD & 1 & 1.33 \\
\hline Kidney disease & 1 & 1.33 \\
\hline Hypertension and testicular cancer & 1 & 1.33 \\
\hline Hypertension Wolff-Parkinson-White syndrome (WPW) & 2 & 1.33 \\
\hline Diabetes,hypertension and cerebrovascular disease & 1 & 2.67 \\
\hline Hypertension and acid peptic disease & 2 & 1.33 \\
\hline Hypertension and Dyslipidemia & 1 & 2.67 \\
\hline Pypertension and Benign prostatic hyperplasia (BPH) & 1.33 \\
\hline Patient without comorbidity & 15 & 20 \\
\hline
\end{tabular}

Table 2: Co-morbidity and length of stay.

\begin{tabular}{|c|c|c|}
\hline Symptoms & Frequencies & \% \\
\hline Chest pain & 35 & 39.77 \\
\hline Chest pain, Shortness of breath & 25 & 28.41 \\
\hline Chest pain, anxiety & 4 & 4.55 \\
\hline Chest pain, shortness of breath, dyspnea & 1 & 1.14 \\
\hline Shortness of breath, anxiety & 1 & 1.14 \\
\hline Chest pain, fever, anxiety & 2 & 2.27 \\
\hline Chest pain, nausea, vomitting & 5 & 5.68 \\
\hline Chest pain, nausea, vomitting, shortness of breath & 3 & 3.41 \\
\hline Chest pain, dyspnea & 3 & 3.41 \\
\hline Chest pain, sweating, palpitition & 2 & 2.27 \\
\hline
\end{tabular}

Table 3: Symptoms. 
Citation: Khan MA, Mairaj M, Khan A, Ahsan M, Ali SI, et al. (2017) Assessment of Direct Cost of Treatment of Ischemic Heart Disease Patient in Tertiary Care Hospital in Karachi. J Bioequiv Availab 9: 353-358. doi: 10.4172/jbb.1000324

stay cost (7.69\%), laboratory and diagnosis cost (10.47\%), hospital stay cost $(7.69 \%)$, surgical procedures $(75.99 \%)$. Surgical procedure was main component of cost of treatment of Ischemic heart disease patients. The cost according to patient age, sex and co morbidity was described and compared in Table 5. Cost based on different co morbidity was determine and it is summarized in Table 6. High cost was recorded in the patient with the age group of 71 to 80 years. The mean expense of patients without comorbidity, with a single type co morbidity and with two or more than two type co-morbidity were Rs. 348260, Rs. 360164, Rs. 355910 and Rs. 456084.00. Patients possess triple co morbidity state consumed a mean cost of Rs. 456084 with a mean LOS of 4.33 days was bigger than single and double co morbidity state as summarized in Table 7 . Highest mean cost of co morbidity was found in the patient with the co morbidity of HTN, DM and CVA i.e., Rs. 588250 as summarized in Table 6.

\section{Factors Associated to High Expense}

\section{Univariate analysis and correlation}

High age, gender, smoking, family history and co-morbidities statistically were not significantly linked with high expense in ischemic heart disease patient. Surgical procedure and length of stay were importantly linked with high expense of treatment of ischemic heart disease. A moderately positive co relation was found between length of stay and the total cost. A very strong positive correlation was found between the surgical procedures and the total mean cost. Diagnosis and laboratory test were not significantly associated with the total mean cost.

\section{Treatment pattern}

Mostly prescribed medication in the ischemic heart disease patient were Aspirin 70 (12.86\%) clopidogrel 73 (13.42\%), metoprolol 27 (12.11\%) and nitroglycerine 35 (15.69\%), bisoprolol 24(10.76\%) (Table 3).

\section{Discussion}

The finding of the present research study can be outlined as follows. The mean aggregate cost of hospitalized IHD patient was Rs. 359975. The costs comprise as follows length of stay cost Rs. 27697; laboratory and diagnosis cost Rs. 37684; medication cost Rs. 21019 and surgical procedure cost Rs 273574 . The percentage of the aggregate cost by every part was as per the following: length of stay cost (7.69\%), laboratory and analysis cost (10.47\%), hospital stay cost (7.69\%), surgical methods (75.99\%). what's more, Surgical methods created the most elevated direct cost $76 \%$. Age and co morbidity was not connected with high cost of IHD. A moderately positive co relation was found between length of stay and the total cost. A very strong positive co relation

\begin{tabular}{|c|c|c|c|}
\hline Cost & Minimum & Maximum & Mean \\
\hline Medication cost & 1266 & 133856 & 21019 \\
\hline Laboratory and diagnosis cost & 5800 & 101700 & 37684 \\
\hline Hospital stay cost & 1400 & 80000 & $10.47 \%$ \\
\hline Surgical procedure cost & 18000 & 825000 & 27697 \\
\hline Total cost & 76729.00 & 904252.00 & 273574 \\
\hline
\end{tabular}

Table 4: Direct cost of treatment.

\begin{tabular}{|c|c|}
\hline Gender & Mean cost \\
\hline male & 357038 \\
\hline female & 360772 \\
\hline total & 359975 \\
\hline Age & Mean cost \\
\hline $30-40$ & 321942 \\
\hline $41-50$ & 379836 \\
\hline $51-60$ & 332842 \\
\hline $61-70$ & 386473 \\
\hline $71-80$ & 398567 \\
\hline $81-85$ & 335308 \\
\hline Total & 359975 \\
\hline
\end{tabular}

Table 5: Cost based on age and gender.

\begin{tabular}{|c|c|c|c|c|c|c|c|c|c|c|c|c|c|c|c|c|c|c|c|}
\hline Comorbidity & $\mathbf{0}$ & $\mathbf{1}$ & $\mathbf{2}$ & $\mathbf{3}$ & $\mathbf{4}$ & $\mathbf{5}$ & $\mathbf{6}$ & $\mathbf{7}$ & $\mathbf{8}$ & $\mathbf{9}$ & $\mathbf{1 0}$ & $\mathbf{1 1}$ & Total \\
\hline Mean cost of comorbidity in Rs & 348260 & 294238 & 372647 & 362832 & 233706 & 295481 & 385333 & 486668 & 588250 & 491460 & 388586 & 224718 & 359975 \\
\hline Mean LOS in days & 2.67 & 1.75 & 3.35 & 2.59 & 1.5 & 3 & 3 & 3 & 2 & 5 & 1 & 2.5 & 2.81 \\
\hline Mean hospital stay cost in Rs & 22413 & 15875 & 33391 & 26872 & 11700 & 33000 & 33000 & 33000 & 22000 & 48500 & 11000 & 33000 & 27697 \\
\hline
\end{tabular}

Note: 0: No comorbidity,1: DM (Diabetes mellitus), 2: HTN (Hypertension), 3: HTN and DM, 4: COPD (Chronic obstructive pulmonary disease), 5: CRF (Chronic renal failure), HTN and DM, 6: HTN (Testicular cancer), 7: HTN,WPW syndrome (wolff Parkinson white syndrome), 8: HTN, DM and CVA (cardiovascular accident disease), 9: HTN, dyslipidemia, 10: HTN, BPH (benign prostatic hyper plasia).

Table 6: Cost based on number of comorbidity.

\begin{tabular}{|c|c|c|c|c|}
\hline Comorbidity & No comorbidity (0) & Single comorbidity (1) & Double comorbidity (2) & Triple comorbidity (3) \\
\hline Mean cost of comorbidity & Rs. 348260 & Rs. 360164 & Rs. 355909.72 & Rs. 456084 \\
\hline Mean LOS & 2.67 days & 3.11 days & 2.45 days & 4.33 days \\
\hline Mean cost of length of stay & Rs. 26700 & Rs. 24575 & Rs. 29834 & Rs. 41167 \\
\hline
\end{tabular}

Table 7: Cost based on no, single, double and triple comorbidity. 
Citation: Khan MA, Mairaj M, Khan A, Ahsan M, Ali SI, et al. (2017) Assessment of Direct Cost of Treatment of Ischemic Heart Disease Patient in Tertiary Care Hospital in Karachi. J Bioequiv Availab 9: 353-358. doi: 10.4172/jbb.1000324

was found between the surgical procedures and the total mean cost. Diagnosis and laboratory test were not significantly associated with the total mean cost.

In a study conducted in UK the researcher determined the total one year expense of IHD to be around $£ 7.06$ billion, which represents the highest of any type of disease in UK. The estimated total direct expense of IHD were $£ 1.73$ billion of which $£ 917$ million (53\%) was consisted for inpatients facility, medical and surgical procedures for the CHD in the UK [8].

In a present study, we determined the mean total cost of hospitalized IHD patient was Rs. 359975. Comparing to other studies in mostly studies the researchers determined the annual cost of treatment of IHD. In our present study, we determined the per episode cost of IHD hospitalized patients. According to a study conducted on American adults and determined that, the total financial effect of IHD was predicted to be $\$ 177$ billion, $\$ 96$ billion in direct medical expense and $\$ 81$ billion in indirect expense. $50 \%$ of the direct expense (\$57 billion) were for inpatient care [5]. In a study conducted in Saudi Arabia according to this study. The overall treatment facility was SAR $8,233,531$ (US $\$ 2,195,608$ ) (SAR1 is equal to US $\$ 3.75$ ) during study period. The mean expense of care per patient was SAR 40,164 $(95 \%$ confidence interval: $35,617-44,711$ ), or SAR 16,066 (US $\$ 4,284.3$ ) per patient per month [6]. In our present study we determined the average medication cost per episode of IHD in hospitalized patient was Rs. 21019 comparing to a study The study was conducted at CamdenOn-Gauley Medical Centre, a non-profit community health centre in rural central West Virginia and determined that the mean per month medication expenses were $\$ 104.77$ for cardiac medications and $\$ 115.54$ for non-cardiac medications, for a total of $\$ 220.31$ [9] where as another study conducted in Brazil researcher determined medication expenses for the treatment of IHD hospitalized patients was (Rs. 1,154.00). Another study conducted in American adults with IHD disease in 2012 estimates the cost of hospital admission with an initial diagnosis of IHD $\$ 24,079$ on average [5]. In a study the researcher determined the mean cost (in 2005 dollars) of initial hospital admission for acute coronary syndromes to be $\$ 22,921$, and their analysis for re-admission in hospital for IHD was $\$ 28,637$ [10]. In a study in the UK, researcher found that $16.9 \%$ of IHD admissions (primary diagnosis) had a secondary diagnosis of diabetes and accounted for $16 \%$ of the costs of the disease [7] in another study the investigator, who also explored the costs associated with a combination of CVD and diabetes, found higher costs in patients with diabetes than in those without that disease, and they reported that diabetes patients with CVD incurred more costs earlier in life than patients with diabetes but no CVD [11]. Elsewhere, in another study the investigator found that for patients with IHD in 2000-2002, costs when they also had hypertension were an additional $\$ 1,900$ (our result was $\$ 2,920$ for 2005 ), and when they had diabetes in addition to IHD were $\$ 3,300$ more (our result was $\$ 5,067$ for 2005) [12]. In the present study cost of the treatment of IHD patient was not increasing with the higher age of the patients and the treatment cost was found higher in female than males. Comparing to another study the investigator found that when IHD was the primary diagnosis the cost of treatment was much larger for those aged 18-44 than it was for the other major subgroups (men, women, and those aged 45-64). He also analysed that men were more likely than women and patients aged 40-54 more likely than those either 18-39 or 55-64 to have IHD as the primary diagnosis rather than a secondary diagnosis is of great interest [5]. Our finding in this study that men were more likely than women and it is more likely to occur between the ages of 51-70 years. In the present study the mean cost was much higher in patient with a CABG surgery as compare to the patient with the PCI surgery. In the present study mean total cost in patient with CABG surgery was Rs. 626837.5 and the total mean cost with a PCI surgery was Rs. 341421.2 which is almost double with CABG surgery. Comparing to other studies according to the researcher he determined that cost for IHD as a primary diagnosis was $\$ 46,757$ when there was CABG surgery, $\$ 19,622$ when there was not [5]. In another study the researcher, reporting more than 2 decades ago, found that the 5-year cost per case was $\$ 32,465$ for CABG surgery and $\$ 26,916$ for angioplasty [13]. Researchers have investigated the factors influencing the high costs of CABG. reducing the number of procedures and/or lowering the unit costs might be cost effective strategies in containing the overall costs associated with IHD [5]. In the present study we determine the median Length of Stay (LOS) was 2 days and mean LOS was 2.8 days, comparing to the other studies the investigator determine 7.47 days as mean length of stay(LOS), was found to be higher than what normally found in the research study (4.9 days) [6].

The following limitation should be considered in interpreting the results. The hospitalization costs were direct medical costs only, while the literature has shown that about half of the total economic burden of IHD is represented by indirect costs such as those for informal care and loss of productivity. Because of shortage of time, or due to patient non-cooperation. The second problem is the depend on the single centre for a limited period of time, which makes it difficult to be extrapolated to the common population, but brief about the specific site I the country. Next problem is availability of other similar national studies for comparison. However, this kind of research is the initial cost of illness study related to IHD in developing country like Pakistan. Which give us beginning thought in regards to current situation, and further thinking and arranging, alongside the fundamental proposal and a model for broad national and further examination.

\section{Conclusion}

In conclusion, this exploration tells us an essential sign of the money related result of IHD. It tells us that IHD is of essential money related burden in Karachi. Surgical methodology was the primary segment of the cost of treatment of IHD. Medication cost was the least expensive cost of treatment of IHD in hospitalized patients. It is additionally found that expanding pattern was not found between the co morbidity and the LOS. Advanced age, sex, smoking, family history and co morbidities factually were not essentially connected with high cost in ischemic coronary illness patients. Surgical technique and hospital stay were fundamentally connected with greater cost of treatment of ischemic coronary illness.

\section{References}

1. Walker R, Whittlesea C (2007) Clinical Pharmacy and Therapeutics ( $5^{\text {th }}$ edn.), Churchill Livingstone, UK.

2. Fraker TD, Finn SD, 2002 Chronic Stable Angina Writing Committee; American College of Cardiology; American Heart Association, et al. (2007) 2007 chronic angina focused update of the ACC/AHA 2002 guidelines for the management of patients with chronic stable angina: A report of the American College of Cardiology/American Heart Association Task Force on Practice Guidelines Writing Group to Develop the Focused Update of the 2002 guidelines for the management of patients with chronic stable angina. Circulation 116: 27622772.

3. Gibbons RJ, Abrams J, Chatterjee K, Daley J, Deedwania PC, et al. (2003) ACC/AHA 2002 guideline update for the management of patients with chronic stable angina-Summary article: A report of the American College of Cardiology/ American Heart Association Task Force on Practice Guidelines (Committee on the Management of Patients with Chronic Stable Angina). Circulation 107: 149158. 
Citation: Khan MA, Mairaj M, Khan A, Ahsan M, Ali SI, et al. (2017) Assessment of Direct Cost of Treatment of Ischemic Heart Disease Patient in Tertiary Care Hospital in Karachi. J Bioequiv Availab 9: 353-358. doi: 10.4172/jbb. 1000324

4. Fox K, Garcia MA, Ardissino D, Buszman P, Camici PG, et al. (2006) Guidelines on the management of stable angina pectoris: Executive summary: The Task Force on the Management of Stable Angina Pectoris of the European Society of Cardiology. Eur Heart J 27: 1341-1381.

5. Wang G, Zhang Z, Ayala C (2010) Hospitalization costs associated with hypertension as a secondary diagnosis among insured patients aged 18-64 years. Am J Hypertens 23: 275-281.

6. Osman AM, Alsultan MS, Al-Mutairi MA (2011) The burden of ischemic heart disease at a major cardiac center in Central Saudi Arabia. Saudi Med J 32: 1279-1284.

7. Currie CJ, Morgan CL, Peters JR (1997) Patterns and costs of hospital care for coronary heart disease related and not related to diabetes. Heart 78: 544-549.

8. Liu JL, Maniadakis N, Gray A, Rayner M (2002) The economic burden of coronary heart disease in the UK. Heart 88: 597-603.
9. Patricoski CT, Steiner G (1999) Cost of medications for patients with ischemic heart disease in a rural family practice center. J Am Board Fam Pract 12: 200 205

10. Menzin J, Wygant G, Hauch O, Jackel J, Friedman M (2008) One-year costs of ischemic heart disease among patients with acute coronary syndromes: findings from a multiemployer claims database. Curr Med Res Opin 24: 461-468.

11. Nichols GA, Brown JB (2002) The impact of cardiovascular disease on medical care costs in subjects with and without type 2 diabetes. Diabetes Care 25 : 482-486.

12. Rosen AB, Cutler DM, Norton DM, Hu HM, Vijan S (2007) The value of coronary heart disease care for the elderly: 1987-2002. Health Aff (Millwood) 26: 111-123.

13. Wittels EH, Hay JW, Gotto AM (1990) Medical costs of coronary artery disease in the United States. Am J Cardiol 65: 432-440. 